\title{
TMS Board of Directors Lead Progress on Strategic Plan
}

\author{
Lynne Robinson
}

Wolfgang Schneider, 2012 TMS president, launched his term at the 2012 TMS-AIME Awards Banquet by outlining the areas of innovation that had been identified as critical to the future success of the organization-volunteerism, education, products and services, and information. These priorities also serve as the basis of the newly adopted TMS strategic plan, and, as Schneider noted in his speech as outgoing TMS president at the 2013 awards program, "I also set my personal goals for my presidential year in these areas."

Schneider further discussed how the TMS Board of Directors has structured its agendas around the plan, to ensure that its focus is trained on strategic issues, rather than operational details. This was clearly evident during the two days at the TMS 2013 Annual Meeting \& Exhibition (TMS2013) in which the TMS Board met, reviewed, and acted on initiatives designed to support the plan's strategic goals. What follows is a brief synopsis of what was presented and considered.

\section{Goal 1: Enhance our Status as a Volunteer-Centric Society}

- An ad hoc Diversity Committee is developing a plan to ensure that TMS leadership positions are filled to reflect the diversity balance of the full TMS membership. The committee is targeting fall 2013 to present its recommendations to the Board.

- During 2012, 959 non-member volunteers became TMS professional members.

- A number of enhancements are under development for the technical committee home pages. Online communities and discussion forums to enhance communications with volunteer groups are being considered.

- To help prepare new volunteer leaders for their roles, TMS is developing online training modules and toolkits for technical committee chairs, while also hosting orientation sessions for new committee leadership.

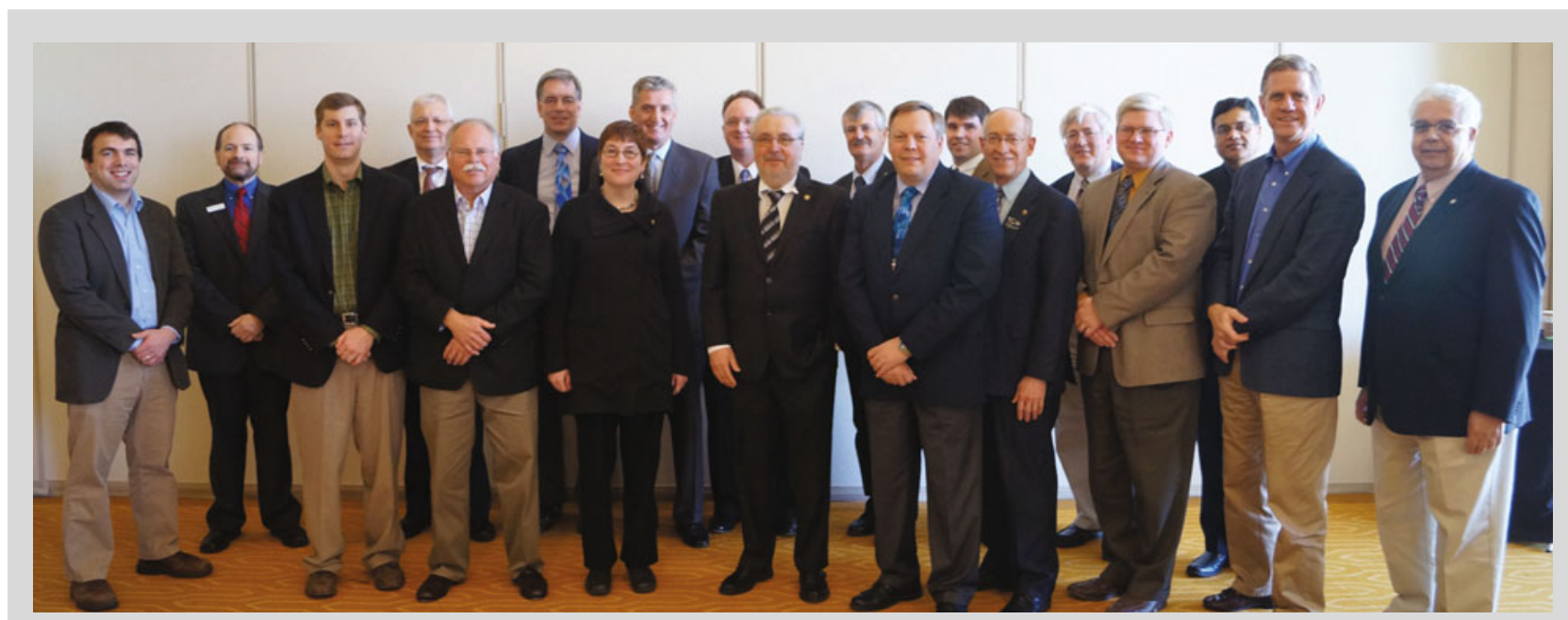

The above photo was taken at the March TMS Board meeting that marked the transition from the 2012 to 2013 Board: Pictured (L-R) are: Edward Herderick (incoming Public \& Governmental Affairs Director); James Robinson (executive director); Jud Ready (Content Development \& Dissemination Director and Co- Chair); David DeYoung (incoming Light Metals Division Chair); Neville Moody (Programming Director); Carl Cady (Content Development \& Dissemination Director and Co-Chair); Elizabeth Holm (2013 president); John Hryn (Light Metals Division Director); Robert Hyers (Financial Planning Officer); Wolfgang Schneider (2012 president); James Sears (Materials Processing \& Manufacturing Division Director); James Foley (incoming Materials Processing \& Manufacturing Division Director); Adrian Deneys (Extraction \& Processing Division Director); Garry Warren (past president); David Shifler (Professional Development Director); David Bahr (Membership \& Student Development Director); Rajiv Mishra (incoming Structural Materials Division Director); Kevin Hemker (Public \& Governmental Affairs Director); Hani Henein (incoming vice president). 
Goal 2: Be the Destination Society for Young Professionals

- Young Leader Professional Development Awards were increased from 10 to 20 for 2013. A survey of past winners demonstrated that the award had significant, positive individual impact and was highly valued.

- Coverage of young professionals was markedly increased in the pages of $J O M$ in 2012, with additional coverage planned for 2013.

- Several new benefits and programs targeting the needs of young professionals have been introduced, including a networking session with more seasoned TMS members and a technical division poster contest introduced at TMS2013.

\section{Goal 3: Sustain and Grow the TMS Core}

- The Board approved the following new programs in support of this strategic goal:

$>2013$ Fundamentals of Friction Stir Welding and Processing Short Course, June 9-11, University of North Texas

2013 Industrial Aluminum Electrolysis Short Course, October 20-25, Doha, Qatar

- At the October 2012 Board meeting, an ad hoc advisory group of TMS members reported on its work to determine key critical core opportunity areas targeted for development. These recommendations have since been communicated to the TMS technical divisions for further review and consideration.

- An ad hoc volunteer team convened for the first time at TMS2013 to develop activities focused on advanced high-strength steels.

- A working group is being convened, consisting of volunteers from the Structural Materials Division and Materials Processing \& Manufacturing Division, to explore the development of

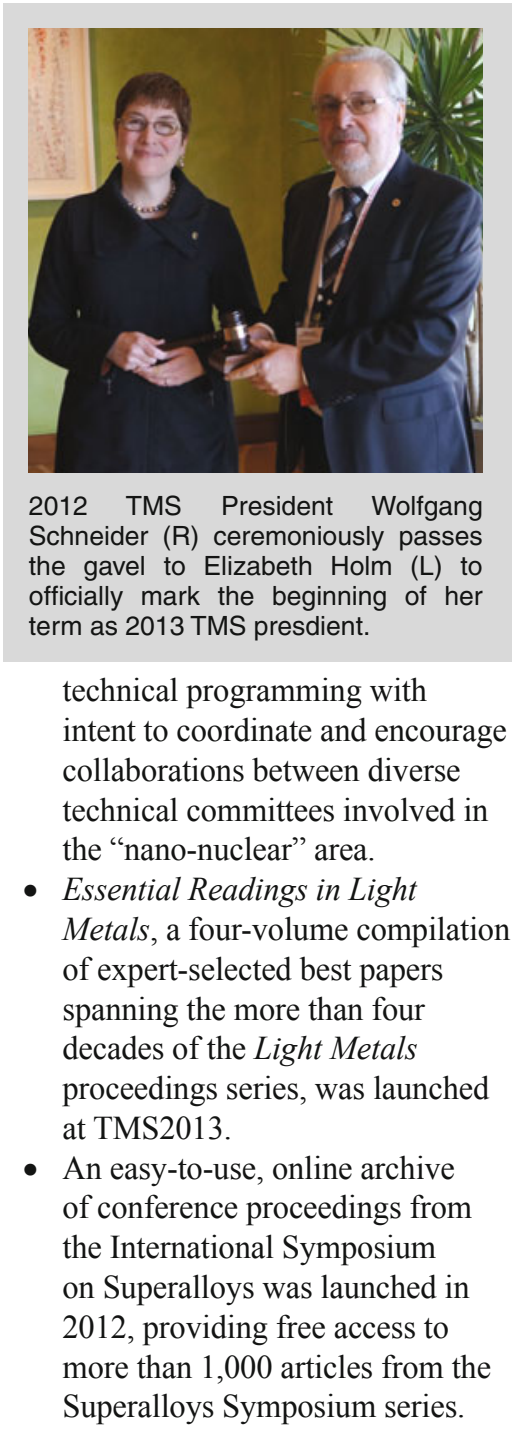

Goal 4: Advance Materials Solutions for Energy and Environmental Challenges

- In support of this goal, the Board approved the launch of Metallurgical and Materials Transactions E: Materials for Energy Systems, a new journal offered in conjunction with ASM International and Springer as publishing partners.

- TMS has entered into an agreement with seven other professional societies as a co-owner of the Carbon Management Technology Conference, scheduled October 21-23, 2013, Alexandria, Virginia.

- Robust programming activity has marked the development of this goal over the last year, with 11 symposia offered at TMS2013 that address energy and environmental challenges, as well as co-locating REWAS 2013: Enabling Materials Resource Sustainability at TMS2013. The Materials and Society Committee also sponsored an Energy Networking Breakfast at TMS2013 that brought together volunteers from energy-related TMS committees to encourage communication and leverage synergies among these groups, especially in programming.

- Developing energy-related issues of TMS journals has been a priority. This has resulted in a special January 2013 issue of Metallurgical and Materials Transactions A dedicated to materials for energy applications, as well as nine energy and environment topics planned for JOM in 2013.

Goal 5: Be the Recognized Home for and Advocate of Materials and Manufacturing Innovation

- The TMS Integrated

Computational Materials

Engineering (ICME)

Implementation Study is on track to be released at the $2^{\text {nd }}$ World Congress on ICME, July 7-11, in Salt Lake City, Utah. Supported by the U.S. Department of Defense, Department of Energy, and National Science Foundation, the study is being developed as a "field manual" for implementing ICME in the near-term in the aerospace, automotive, and maritime industries.

- The Materials Genome Initiative (MGI) Digital Data Platform, a collaborative effort of the National Institute of Standards and Technology (NIST) and TMS, was launched at TMS2013. This resource supports interactions within the various sub-disciplines of materials science and engineering by enabling users to build and join online communities, especially those focused on the creation and sharing of data.

- In support of this goal, the Board approved the 2nd International Conference on 3D Materials Science 2014, to be held June 29July 2, 2014, in Annecy, France. 